\title{
Identification and characterization of novel single nucleotide polymorphism markers for fat deposition in muscle tissue of pigs using amplified fragment length polymorphism
}

\author{
Pantaporn Supakankul ${ }^{1,2,3}$, Tanavadee Kumchoo ${ }^{1}$, and Supamit Mekchay ${ }^{1, *}$
}

\footnotetext{
* Corresponding Author: Supamit Mekchay Tel: +66-53-944092, Fax: +66-53-225221,

E-mail: supamit.m@cmu.ac.th

'Department of Animal and Aquatic Sciences, Faculty of Agriculture, Chiang Mai University, Chiang Mai 50200, Thailand

${ }^{2}$ Center of Excellence on Agricultural Biotechnology: (AG-BIO/PERDO-CHE), Bangkok 10900, Thailand ${ }^{3}$ Human and Animal Biotechnology Program, Graduate School, Chiang Mai University, Chiang Mai 50200, Thailand
}

Submitted Mar 9, 2016; Revised Jun 26, 2016; Accepted Sept 8, 2016
Objective: This study was conducted to identify and evaluate the effective single nucleotide polymorphism (SNP) markers for fat deposition in the longissimus dorsi muscles of pigs using the amplified fragment length polymorphism (AFLP) approach.

Methods: Sixty-four selective primer combinations were used to identify the AFLP markers in the 20 highest- and 20 lowest-intramuscular fat (IMF) content phenotypes. Five AFLP fragments were converted into simple codominant SNP markers. These SNP markers were tested in terms of their association with IMF content and fatty acid (FA) composition traits in 620 commercially crossbred pigs.

Results: The SSC7 g.4937240C > G marker showed an association with IMF content $(p<0.05)$. The SSC9 g.5496647_5496662insdel marker showed a significant association with IMF content and arachidonic levels $(\mathrm{p}<0.05)$. The SSC10 g.71225134G $>$ A marker revealed an association with palmitoleic and $\omega 9$ FA levels $(p<0.05)$, while the SSC17 g.61976696G $>$ T marker showed a significant association with IMF content and FA levels of palmitoleic, eicosenoic, arachidonic, monounsaturated fatty acids, and $\omega 9$ FA levels. However, no significant association of SSC8 g.47338181G $>$ A was observed with any IMF and FA levels in this study.

Conclusion: Four SNP markers (SSC7 g.4937240C>G, SSC9 g.5496647_5496662insdel, SSC10 g.71225134G $>$ A, and SSC17 g.61976696G $>$ T) were found to be associated with IMF and/or FA content traits in commercially crossbred pigs. These findings provide evidence of the novel SNP markers as being potentially useful for selecting pigs with the desirable IMF content and FA composition.

Keywords: Amplified Fragment Length Polymorphism (AFLP); Intramuscular Fat; Fatty Acid; Pig

\section{INTRODUCTION}

Increasing levels of intramuscular fat (IMF) content has a positive impact on the meat quality of pork [1]. The fatty acid (FA) composition of pork is an important factor in defining lipid quality due to its implications for human health [2]. Fat deposition and fatty acid composition in pork are very complex traits that are likely to be controlled by a variety of genes [3]. There have been several attempts made to identify the quantitative trait loci (QTL) for IMF content and FA composition in pigs using microsatellite markers $[2,4,5]$. Recently, advances in the highdensity single nucleotide polymorphisms (SNPs) chip approach have allowed for the genotyping of a large number of SNPs throughout the genome [6]. The genome wide association study approach has been carried out to detect QTLs affect on IMF and FA content in the muscle tissue of pigs [7-9]. Empirical evidence of identifying QTL for IMF and FA content traits have been successfully performed using F2 or crossbred experimental populations, e.g. Iberian and Land- 
race [7], White Duroc and Erhualian [9], Yorkshire and Korean native pigs [10]. However, QTL segregation must be confirmed in different breeds for successful marker-assisted and genomic selection [5]. Very few research efforts have undertaken the QTL for IMF and FA content traits in the commercial line pig breeds $[4,8]$. Genome scanning of chromosome regions for IMF and FA content traits in the commercial lines is important for improving meat quality in the pig production process.

Amplified fragment length polymorphism (AFLP) genome scan is an alternative relevant approach in detecting potential genetic markers with specific traits. It is a robust and highlythroughout tool for screening the whole genome and produces a large number of markers that can be converted to simple codominant locus-specific markers without prior knowledge of the specific sequences [11]. The AFLP approach has been used to successfully identify the QTLs for meat quality and carcass traits in both pigs and cattle $[11,12]$. In this present study, we identified and evaluated the effects of novel SNP markers for IMF and FA composition in the longissimus dorsi (LD) muscle tissue of the commercially crossbred pigs using the AFLP approach.

\section{MATERIALS AND METHODS}

\section{Animals, DNA isolation, intramuscular fat, and fatty acid content determination}

The study protocol was approved by the Animal Ethics Committee of the Faculty of Agriculture, Chiang Mai University, Thailand. A total of 620 commercially crossbred pigs (Duroc and Large WhitexLandrace) (322 gilts and 298 barrows) were reared under commercial conditions. Animals were slaughtered according to applicable standards at the slaughter-weight of $90 \mathrm{~kg}$. The LD muscles were collected from the 10th rib for DNA extraction and for IMF content measurement. The genomic DNA was extracted according to the standard phenol-chloroform protocol. The IMF content of each LD sample was determined by the ether extraction method and expressed as the percentage of IMF in fresh meat. Fatty acid composition was determined by using a gas chromatography apparatus (SCION 456-GC, Bruker Daltonic Inc, Fremont, CA, USA) with a RT-2560 capillary column (RESTEK, Bellefonte, PA, USA). Fatty acid composition was reported as the percentage of total fatty acids.

\section{Amplified fragment length polymorphism analysis}

The AFLP analysis was conducted by selecting the specimens with the 20 highest- and 20 lowest-IMF content from the 620 commercially crossbred pigs. The AFLP procedures were performed according to the previous study [11]. Genomic DNA samples (250 ng) were digested with FastDigest EcoRI and subsequently with FastDigest TaqI (Fermentas, Hanover, MD, USA) based on the manufacturer's instructions. Restriction fragments were ligated to $10 \mathrm{pmol}$ of EcoRI-adapters and 50 pmol of TaqI-adapters in $30 \mu \mathrm{L}$ of the ligation mixture that contained $1 \mathrm{U}$ T4 DNA ligase. The reaction was incubated at $20^{\circ} \mathrm{C}$ for $2 \mathrm{~h}$ and then at $4^{\circ} \mathrm{C}$ overnight. The ligated DNA fragments were diluted 1:5 with double-distilled water and used as a template for amplification. Pre-selective amplification was performed in $25 \mu \mathrm{L}$ containing $10 \mathrm{ng}$ of diluted ligation fragments, $1 \times$ Taq Buffer $(20 \mathrm{mM}$ Tris- $\mathrm{HCl}, \mathrm{pH}$ 8.4, $50 \mathrm{mM}$ $\left(\mathrm{NH}_{4}\right)_{2} \mathrm{SO}_{4}$; Fermentas, USA), $3.0 \mathrm{mM} \mathrm{MgCl}, 0.25 \mathrm{mM}$ each of the four dNTPs, $0.25 \mathrm{U}$ Taq DNA polymerase (Fermentas, USA), 4 pmol of EcoRI-N primer (E-A) and 4 pmol of TaqI-N primer (T-C). The polymerase chain reaction (PCR) program was performed as follows: $3 \mathrm{~min}$ at $94^{\circ} \mathrm{C}, 20$ cycles of $30 \mathrm{~s}$ at $94^{\circ} \mathrm{C}, 1 \mathrm{~min}$ at $56^{\circ} \mathrm{C}$ and $1 \mathrm{~min}$ at $72^{\circ} \mathrm{C}$, followed by $5 \mathrm{~min}$ at $72^{\circ} \mathrm{C}$, and ended at $4^{\circ} \mathrm{C}$. The pre-amplification products were diluted 1:20 with double-distilled water and then used as DNA templates for selective-amplification. The selective amplification was carried out with 64 primer combinations (E-ANN and T$\mathrm{CNN}$ ). The reaction was carried out in $12.5 \mu \mathrm{L}$ containing 2.5 $\mu \mathrm{L}$ of diluted pre-selective amplification products, $1 \times$ Taq Buffer (20 mM Tris-HCl, pH 8.4, $50 \mathrm{mM}\left(\mathrm{NH}_{4}\right)_{2} \mathrm{SO}_{4}$; Fermentas, USA), $3.0 \mathrm{mM} \mathrm{MgCl} 2,0.25 \mathrm{mM}$ of each of the four dNTPs, $0.25 \mathrm{U}$ Taq DNA polymerase (Fermentas, USA) and 2 pmol of EcoRINNN primer and 2 pmol of TaqI-NNN primer. A touchdown thermal protocol was performed, as follows: $3 \mathrm{~min}$ at $94^{\circ} \mathrm{C}, 2$ cycles of $30 \mathrm{~s}$ at $94^{\circ} \mathrm{C}, 1 \mathrm{~min}$ at $62^{\circ} \mathrm{C}$ and $1 \mathrm{~min}$ at $72^{\circ} \mathrm{C}$, reduction annealing temperature by $2^{\circ} \mathrm{C}$ in four steps of three cycles each. The PCR was proceeded with 20 cycles of $30 \mathrm{~s}$ at $94^{\circ} \mathrm{C}, 1$ min at $52^{\circ} \mathrm{C}$ and $1 \mathrm{~min}$ at $72^{\circ} \mathrm{C}$, followed by $5 \mathrm{~min}$ at $72^{\circ} \mathrm{C}$, and was ended at $4^{\circ} \mathrm{C}$. An aliquot of the selective amplification was added 1:10 with formamide-containing loading buffer. Denatured products $(10 \mu \mathrm{L})$ were loaded on $6 \%$ urea-containing polyacrylamide gels and electrophoresis at a constant power of $55 \mathrm{~W}$ for $3 \mathrm{~h}$. The gels were visualized using silver staining.

\section{Cloning and sequencing of AFLP fragments}

The AFLP fragments of interest were excised from the gel samples and eluted in $20 \mu \mathrm{L}$ of $1 \times$ PCR buffer at $4^{\circ} \mathrm{C}$ overnight. The solution was boiled at $95^{\circ} \mathrm{C}$ for $10 \mathrm{~min}$ and $5 \mu \mathrm{L}$ of DNA fragments were reamplified using the same primer for the selective amplification of the PCR conditions. The PCR products were gel purified and cloned into pGEM-T Easy vector (Promega, Madison, WI, USA) according to the manufacturer's instructions. The inserted clones were sequenced using automated sequencer CEQ8000 (Beckman Coulter, Brea, CA, USA). The sequences were analyzed for homology with NCBI (http://www.ncbi.nlm. nih.gov/BLAST/) and Ensembl (http://asia.ensembl.org/Multi/ blastview) databases.

\section{Conversion of AFLP markers into simple SNP markers and SNP genotyping}

In order to discover the polymorphisms in the restriction sites 
Table 1. Primer sequences used for genotyping the SNP markers in pigs

\begin{tabular}{|c|c|c|c|c|}
\hline SNP marker & Primer sequence ( $5^{\prime}$ to $\left.3^{\prime}\right)$ & Size (bp) & $\mathrm{T}_{\mathrm{m}}\left({ }^{\circ} \mathrm{C}\right)$ & Restriction enzyme \\
\hline SSC7 g. $4937240 C>G$ & $\begin{array}{l}\text { F: TGTCTCTCCTCTTGCCCATC } \\
\text { R: CAGTCAAGCCTCTTCTTGTC }\end{array}$ & 286 & 58 & BsuRI \\
\hline SSC8 g.47338181G >A & $\begin{array}{l}\text { F: CTGGCATCATCACCCTAAAC } \\
\text { R: CCACACCAGTCTTGTGAACT }\end{array}$ & 288 & 60 & Taql \\
\hline SSC9 g.5496647_5496662insdel & $\begin{array}{l}\text { F: GCTATGGCTTTCCCTTCTGC } \\
\text { R: AGCTTCAGAGCGTCCACGAA }\end{array}$ & $216 / 200$ & 58 & 16-bp Ins/Del \\
\hline SSC17 g.61976696G > T & $\begin{array}{l}\text { F: CTTTCTGGGTGTTCCCTCCA } \\
\text { R: CAGGTAACAGACTGGCAGAG }\end{array}$ & 384 & 58 & Hin6l \\
\hline
\end{tabular}

SNP, single nucleotide polymorphism.

and within the AFLP fragments, the PCR fragments obtained from pigs of both extreme phenotypes were comparatively sequenced. Primer sequences were designed by covering the AFLP fragments based on the flanking sequence information acquired from the Ensembl (http://asia.ensembl.org/index.html) database (Table 1). The New England BioLabs cutter (NEBcutter) software (http://nc2.neb.com/NEBcutter2/) was used to identify the specific restriction enzymes for each SNP marker. To identify the SNP genotypes, the PCR reaction was carried out in a final volume of $20 \mu \mathrm{L}$ containing $50 \mathrm{ng}$ of genomic DNA, $1 \times \mathrm{Taq}$ Buffer (20 mM Tris- $\mathrm{HCl}$, pH 8.4, $50 \mathrm{mM}\left(\mathrm{NH}_{4}\right)_{2} \mathrm{SO}_{4}$; Fermentas, USA), $1.5 \mathrm{mM} \mathrm{MgCl}_{2}, 0.25 \mathrm{mM}$ each of the dNTPs, $0.2 \mathrm{U}$ Taq DNA polymerase (Fermentas, USA) and 2 pmol of each primer (Table 1). A thermal protocol was performed as follows: $3 \mathrm{~min}$ at $94^{\circ} \mathrm{C} ; 38$ cycles of $30 \mathrm{~s}$ at $94^{\circ} \mathrm{C}, 30 \mathrm{~s}$ at $58^{\circ} \mathrm{C}$ to $60^{\circ} \mathrm{C}$ and $30 \mathrm{~s}$ at $72^{\circ} \mathrm{C}$; and the final step was done for $5 \mathrm{~min}$ at $72^{\circ} \mathrm{C}$. The amplified fragments were digested with restriction enzymes (Table 1) and separated on $8 \%$ polyacrylamide gel electrophoresis. The gels were visualized using silver staining.

\section{Statistical analysis}

The genotype and allele frequencies of the SNP markers were calculated. Significance of the AFLP fragment frequencies between the extreme two groups (high- and low-IMF contents) was tested using the chi-square analysis. Association analysis of the simple SNP markers with IMF content and FA composition traits was examined using a general linear model. The following statistical model was used:

$$
y_{i j k l m n}=\mu+\operatorname{sire}_{i}+\text { dam }_{j}+\operatorname{sex}_{k}+\text { batch }_{l}+\text { marker }_{m}+\mathrm{e}_{i j k l m n}
$$

Where $y_{i j k l m n}$ represents the observed value of the phenotype traits, $\mu$ is representative of the population mean average of the measurements, sire $_{i}$ represents the fixed effect of the sires $(i=$ 1 to 5$), d^{2} m_{j}$ represents the fixed effect of the dams ( $j=1$ to 15$)$,

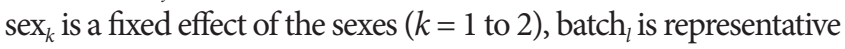
of the fixed effect of the slaughter batch ( $l=1$ to 12$),$ marker $_{m}$ is representative of the fixed effect of the marker genotypes $(m$
$=1$ to 3 ), and $e_{i k l m n}$ represents any random error. Significance was detected at the $5 \%$ level of all statistical analyzes.

\section{RESULTS}

\section{AFLP analysis}

Sixty-four selective primer combinations were used to identify the AFLP markers for IMF content. A total of 1,454 markers were observed with an average of 35 amplified fragments per primer combination. The majority of the AFLP fragments ranged in size from 50 to $800 \mathrm{bp}$. From these, 145 AFLP markers were found to be polymorphic between the two extreme IMF content groups. A representative AFLP marker and the associated fragment profile are shown in Figure 1. Twelve polymorphic fragments revealed the most striking significant differences between the two groups of high- and low-IMF contents $(\mathrm{p}<0.05)$. These AFLP fragments were obtained from the selective primer combinations as shown in Table 2. From these, the AFLP fragments were cloned, sequenced and used as candidate markers for fat deposition in muscle tissue.

\section{Identification of AFLP fragments and chromosome locations}

Five AFLP fragments were successfully sequenced. Homology searching and in silico mapping were performed using BLAST and Ensembl databases. All AFLP fragments were homology identified to the genomic DNA sequence of the pigs (Table 3). An AFLP fragment shared significant similarities with a known gene of pigs. The AFLP2 fragment showed a significant level of similarity with the porcine ankyrin repeat domain 16 ( $A N$ KRD16) gene (GenBank accession no. XM_013980330.1) and was located on chromosome SSC10 at $71.2 \mathrm{Mb}$. On the other hand, four AFLP fragments (AFLP1, AFLP3, AFLP7, and AFLP10) exhibited sequence identity with porcine DNA sequences (90\% to $100 \%$ ) and were located on chromosome SSC17 at position $61.97 \mathrm{Mb}$, SSC7 at $4.93 \mathrm{Mb}$, SSC9 at 5.49 $\mathrm{Mb}$, and SSC8 at $47.33 \mathrm{Mb}$, respectively (Table 3).

To identify the causal polymorphism of these AFLP markers, 


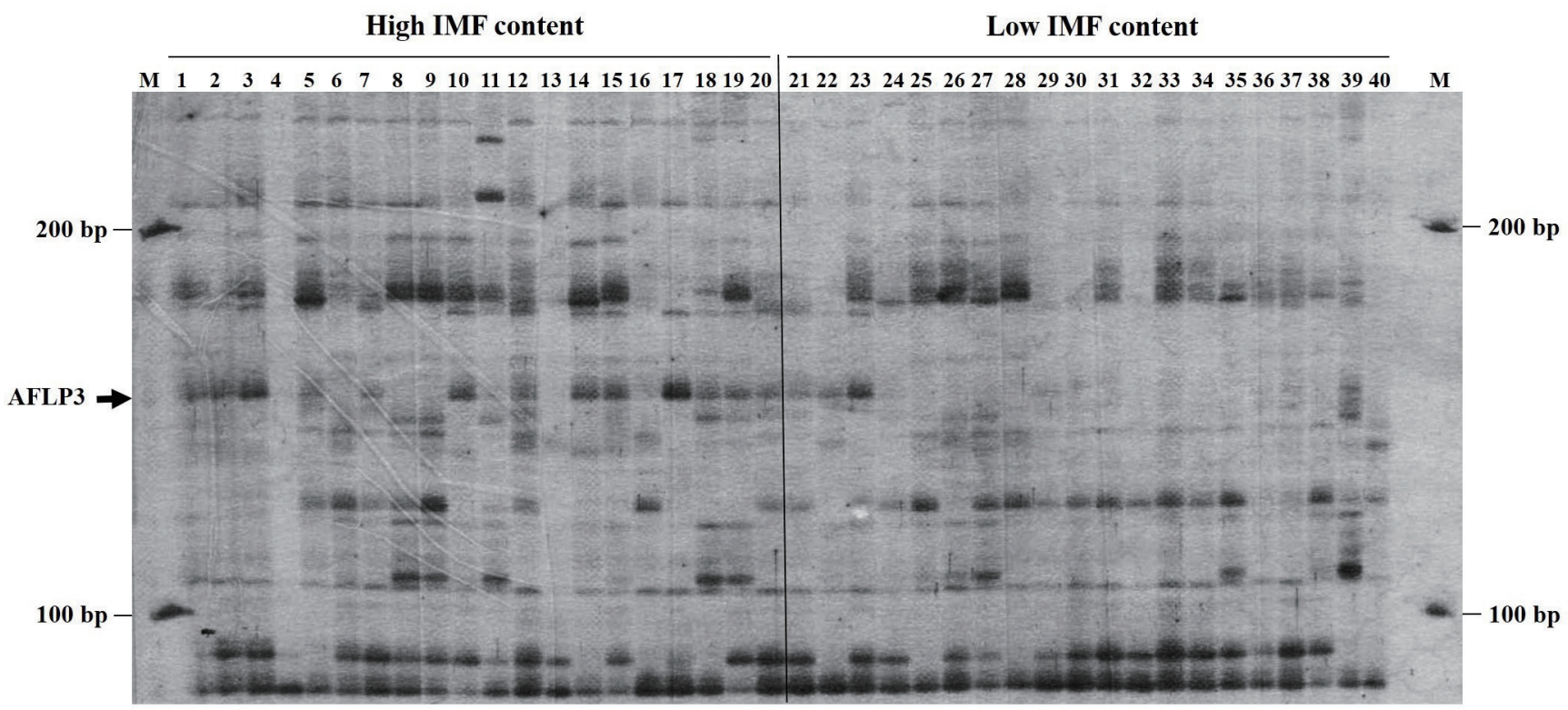

Figure 1. A representative AFLP profile, of two extremely high and low IMF contents, was obtained with the primer combination E-AGC/T-CCA. The arrow indicates the potential AFLP fragment (AFLP3) for IMF content trait that was recovered from gels and was then analyzed further. Lane $\mathrm{M}=100$ bp DNA ladder. Lanes 1 to 20 represent DNA samples with high IMF content phenotypes and Lanes 21 to 40 represent DNA samples with low IMF content phenotypes. AFLP, amplified fragment length polymorphism; IMF, intramuscular fat.

Table 2. Selected AFLP markers based on fragment frequency between high- and low-IMF contents in muscle tissue of pigs

\begin{tabular}{|c|c|c|c|c|c|}
\hline \multirow{2}{*}{ Marker } & \multirow{2}{*}{$\begin{array}{l}\text { Primer } \\
\text { combination }\end{array}$} & \multirow{2}{*}{$\begin{array}{c}\text { Fragment } \\
\text { size (bp) }\end{array}$} & \multicolumn{2}{|c|}{ Frequency } & \multirow{2}{*}{$\begin{array}{c}\text { p-value } \\
\left(x^{2}\right)\end{array}$} \\
\hline & & & High-IMF & Low-IMF & \\
\hline AFLP1 & E-ACC/T-CCG & 223 & 0.25 & 0.45 & 0.0157 \\
\hline AFLP2 & E-ACG/T-CTG & 71 & 0.30 & 0.48 & 0.0230 \\
\hline AFLP3 & E-AGC/T-CCA & 167 & 0.15 & 0.43 & 0.0013 \\
\hline AFLP4 & E-AGC/T-CTG & 136 & 0.48 & 0.28 & 0.0106 \\
\hline AFLP5 & E- AGG/T-CAT & 84 & 0.18 & 0.35 & 0.0574 \\
\hline AFLP6 & E- AGG/T-CCA & 188 & 0.03 & 0.20 & 0.0230 \\
\hline AFLP7 & E-ATC/T-CGT & 79 & 0.05 & 0.28 & 0.0069 \\
\hline AFLP8 & E-ATC/T-CGA & 176 & 0.50 & 0.18 & $<0.0001$ \\
\hline AFLP9 & E-ACG/T-CTG & 152 & 0.15 & 0.35 & 0.0268 \\
\hline AFLP10 & E-AGC/T-CTG & 171 & 0.05 & 0.23 & 0.0336 \\
\hline AFLP11 & E-ATC/T-CGA & 198 & 0.15 & 0.45 & 0.0003 \\
\hline AFLP12 & E-ACG/T-CTG & 145 & 0.10 & 0.28 & 0.0500 \\
\hline
\end{tabular}

AFLP, amplified fragment length polymorphism; IMF, intramuscular fat.

the primers were designed based on the flanking sequence information that covered the AFLP fragments. The DNA fragments of the pigs that represented the IMF content extremes were amplified and comparatively sequenced. Four fragments (AFLP1,
AFLP2, AFLP3, and AFLP10) were identified as SNP at the TaqI restriction site, selective sites or within the AFLP fragments and were named as SSC17 g.61976696G $>$ T, SSC10 g.712251 34G>A, SSC7 g.4937240C>G, and SSC8 g.47338181G>A, respectively. The other fragment (AFLP7) was identified as insertion/deletion (Ins/Del) in the AFLP fragment and was named as SSC9 g.5496647_5496662insdel (16-bp Ins/Del).

\section{Association of SNP markers with IMF content and FA composition}

In order to elucidate the effect of the SNP markers (derived from AFLP fragments) on IMF content and FA composition, the relevant traits were investigated in pigs. Five SNP markers (SSC7 g.4937240C>G, SSC8 g.47338181G>A, SSC9 g.5496647_5496 662insdel, SSC10 g.71225134G>A, and SSC17 g.61976696G>T) were genotyped in 620 commercially crossbred pigs. Genotype and allele frequencies of these five SNP markers are shown in Table 4. The results of the association analysis of five SNP markers and the fat deposition traits in the LD muscles are shown in Table 5 to 8 . The SSC7 g.4937240C>G marker was found to be significantly associated with IMF content but, showed no

Table 3. Characterization of AFLP markers for fat deposition in muscle tissue of pigs

\begin{tabular}{llcccc}
\hline Marker & Homology & GenBank accession no. & Chromosome location (Mb) & Base pair identity (\%) & Mapped close to gene \\
\hline AFLP1 & porcine DNA & NC_010459.4 & SSC17 (61.97) & $223 / 223(100)$ & CYP24A1, DOK5 \\
AFLP2 & ANKRD16 & NC_010452.3 & SSC10 (71.22) & $71 / 71(100)$ & ANKRD16 \\
AFLP3 & porcine DNA & NC_010449.4 & SSC7 (4.93) & $167 / 169(99)$ & RREB1 \\
AFLP7 & porcine DNA & NC_010451.3 & SSC9 (5.49) & $63 / 79(90)$ & OR51V1 \\
AFLP10 & porcine DNA & NC_010450.3 & SSC8 (47.33) & $171 / 171(100)$ & GUCY1B3 \\
\hline
\end{tabular}

AFLP, amplified fragment length polymorphism; ANKRD16, ankyrin repeat domain 16; CYP24A1, cytochrome P450 family 24 subfamily A member 1; DOK5, docking protein 5; GUCY1B3, guanylate cyclase 1 soluble beta 3; OR51V1, olfactory receptor family 51, subfamily $\mathrm{V}$, member $1 ; R R E B 1$, ras responsive element binding protein 1 . 
Table 4. Genotype and allele frequencies of SNP markers in commercially crossbred pigs

\begin{tabular}{|c|c|c|c|c|c|c|}
\hline \multirow{2}{*}{ SNP } & \multirow{2}{*}{$\mathrm{N}$} & \multicolumn{3}{|c|}{ Genotype frequency } & \multicolumn{2}{|c|}{ Allele frequency } \\
\hline & & AA & $A B$ & BB & $A^{1)}$ & B \\
\hline SSC7 g.4937240C > G & 565 & 0.48 & 0.36 & 0.16 & 0.65 & 0.35 \\
\hline SSC8 g. $47338181 \mathrm{G}>\mathrm{A}$ & 513 & 0.64 & 0.24 & 0.12 & 0.76 & 0.24 \\
\hline SSC9 g.5496647_5496662insdel & 585 & 0.28 & 0.58 & 0.14 & 0.57 & 0.43 \\
\hline SSC10 g.71225134G $>A$ & 601 & 0.81 & 0.19 & 0.00 & 0.90 & 0.10 \\
\hline SSC17 g.61976696G > T & 570 & 0.52 & 0.30 & 0.18 & 0.67 & 0.33 \\
\hline
\end{tabular}

SNP, single nucleotide polymorphism.

1) Allele A represents major alleles of the SSC7 g.4937240C, SSC8 g.47338181A, SSC9 g.5496647_5496662del, SSC10 g.71225134A and SSC17 g.61976696G loci, respectively and allele B represents minor alleles of the SSC7 g.4937240G, SSC8 g.47338181G, SSC9 g.5496647_5496662ins, SSC10 g.71225134G and SSC17 g.61976696T loci, respectively.

association with any FA levels (Table 5). The SSC9 g.5496647_ 5496662insdel marker showed a significant association with IMF content and arachidonic levels (Table 6). No association of the SSC10 g.71225134G>A marker with IMF content was observed. However, this marker was significantly associated with palmitoleic and $\omega 9$ FA levels (Table 7). The SSC17 g.61976696G $>$ T marker was significantly associated with IMF content and FA levels of palmitoleic, eicosenoic, arachidonic, monounsaturated fatty acids (MUFA), and $\omega 9$ FA levels (Table 8). However, no significant association of SSC8 g.47338181G $>$ A with any IMF and FA composition values was observed in this study (data not shown).

\section{DISCUSSION}

The AFLP approach is generally considered a powerful method of genome-wide scan technology for the QTL identification of complex traits. Several studies have successfully identified the QTLs and candidate genes for growth, meat quality and carcass traits in various livestock species $[11,12]$. In the present study, the genome-wide scan for fat deposition in the muscle tissue of pigs was investigated using the AFLP approach. The selective markers were then further elucidated to determine an association with IMF content and FA levels. Four of the five candidate markers showed a significant association with IMF content and/or FA composition.

In this study, the SSC7 g.4937240C > G marker revealed a significant association with IMF content in the crossbred pigs. This result is consistent with those of previous studies in pigs that were used to which identify the QTLs for IMF content on SSC7 at position 2.0 to $11.6 \mathrm{Mb}$ [13]. The SSC7 g.4937240C $>\mathrm{G}$ marker obtained from the primer combination E-AGC/T-CCA

Table 5. Association of the SSC7 g.4937240C > G marker with IMF content and fatty acid composition traits in longissimus dorsi muscles in commercially crossbred pigs

\begin{tabular}{|c|c|c|c|c|}
\hline \multirow{2}{*}{ Traits (\%) } & \multicolumn{3}{|c|}{ Genotypes (Least squares mean \pm standard error) } & \multirow{2}{*}{ p-value } \\
\hline & $C C(n=180)$ & CG $(n=129)$ & GG $(n=63)$ & \\
\hline IMF & $2.628 \pm 0.170^{b}$ & $2.364 \pm 0.177^{\mathrm{a}}$ & $2.212 \pm 0.258^{\mathrm{a}}$ & 0.0454 \\
\hline C14:0 (Myristic) & $1.175 \pm 0.062$ & $1.020 \pm 0.072$ & $1.074 \pm 0.127$ & 0.1241 \\
\hline C16:0 (Palmitic) & $13.605 \pm 1.049$ & $11.539 \pm 1.221$ & $12.498 \pm 2.131$ & 0.2944 \\
\hline C18:0 (Stearic) & $12.366 \pm 0.897$ & $10.827 \pm 1.044$ & $10.999 \pm 1.823$ & 0.3275 \\
\hline C20:0 (Arachidic) & $0.303 \pm 0.067$ & $0.278 \pm 0.078$ & $0.187 \pm 0.136$ & 0.7342 \\
\hline SFA & $24.451 \pm 1.429$ & $23.666 \pm 1.663$ & $25.759 \pm 2.903$ & 0.1074 \\
\hline C16:1n-9 (Palmitoleic) & $3.957 \pm 0.320$ & $3.534 \pm 0.373$ & $4.433 \pm 0.651$ & 0.4641 \\
\hline C18:1n-9 (Oleic) & $32.675 \pm 1.924$ & $32.657 \pm 2.239$ & $31.358 \pm 3.909$ & 0.9581 \\
\hline C20:1n-9 (Eicosenoic) & $2.394 \pm 0.403$ & $2.237 \pm 0.469$ & $1.559 \pm 0.820$ & 0.6521 \\
\hline MUFA & $39.027 \pm 1.960$ & $38.429 \pm 2.281$ & $37.351 \pm 3.981$ & 0.9093 \\
\hline C18:2n-6 (Linoleic) & $24.373 \pm 1.592$ & $26.243 \pm 1.852$ & $27.504 \pm 3.234$ & 0.1572 \\
\hline C18:3n-6 (Linolenic) & $0.124 \pm 0.044$ & $0.155 \pm 0.051$ & $0.145 \pm 0.090$ & 0.8318 \\
\hline C20:2n-6 (Eicosadienoic) & $1.682 \pm 0.251$ & $1.548 \pm 0.292$ & $1.925 \pm 0.509$ & 0.8332 \\
\hline C20:3n-6 (Homolinolenic) & $0.142 \pm 0.050$ & $0.274 \pm 0.058$ & $0.185 \pm 0.102$ & 0.1097 \\
\hline C20:4n-6 (Arachidonic) & $0.166 \pm 0.119$ & $0.224 \pm 0.139$ & $0.232 \pm 0.143$ & 0.3448 \\
\hline PUFA & $26.489 \pm 1.610$ & $28.447 \pm 1.873$ & $29.429 \pm 2.270$ & 0.1637 \\
\hline$\omega 3 \mathrm{FA}$ & $1.311 \pm 0.263$ & $1.539 \pm 0.306$ & $1.473 \pm 0.535$ & 0.2251 \\
\hline$\omega 6 \mathrm{FA}$ & $24.993 \pm 1.651$ & $27.031 \pm 1.921$ & $27.004 \pm 1.353$ & 0.1657 \\
\hline$\omega 9 \mathrm{FA}$ & $36.633 \pm 1.944$ & $36.192 \pm 2.261$ & $37.792 \pm 3.948$ & 0.9673 \\
\hline
\end{tabular}

IMF, intramuscular fat content; SFA, saturated fatty acids (C14:0+C16:0+C18:0+C20:0); MUFA, monounsaturated fatty acids (C16:1n-9+C18:1n-9+C20:1n-9); PUFA, polyunsaturated fatty acids (C18:2n-6+C18:3n-6+C20:2n-6+C20:3n-6+C20:4n-6); $\omega 3$ fatty acids (C18:3n-3+C20:5n-3+C22:6n-3); $\omega 6$ fatty acids (C18:2n-6+C18:3n-6+C20:3n-6); $\omega 9$ fatty acids (C16:1n-9+C18:1n-9).

a,b Values in each row with different superscript letters are considered significantly different $(p<0.05)$. 
Table 6. Association of the SSC9 g.5496647_5496662insdel marker with IMF content and fatty acid composition traits in longissimus dorsi muscles in commercially crossbred pigs

\begin{tabular}{|c|c|c|c|c|}
\hline \multirow{2}{*}{ Traits (\%) } & \multicolumn{3}{|c|}{ Genotypes (Least squares mean \pm standard error) } & \multirow{2}{*}{ p-valu } \\
\hline & InsIns $(n=55)$ & InsDel $(n=230)$ & DelDel $(n=105)$ & \\
\hline IMF & $1.716 \pm 0.269^{a}$ & $2.648 \pm 0.159^{a}$ & $2.526 \pm 0.304^{b}$ & 0.0155 \\
\hline C14:0 (Myristic) & $1.150 \pm 0.243$ & $1.096 \pm 0.073$ & $1.025 \pm 0.103$ & 0.7189 \\
\hline C16:0 (Palmitic) & $13.729 \pm 3.503$ & $13.287 \pm 1.054$ & $11.538 \pm 1.487$ & 0.4236 \\
\hline C18:0 (Stearic) & $10.347 \pm 2.861$ & $12.200 \pm 0.861$ & $12.427 \pm 1.215$ & 0.8258 \\
\hline C20:0 (Arachidic) & $0.380 \pm 0.213$ & $0.348 \pm 0.064$ & $0.326 \pm 0.090$ & 0.5580 \\
\hline SFA & $25.307 \pm 4.809$ & $26.933 \pm 1.448$ & $25.316 \pm 2.042$ & 0.6706 \\
\hline C16:1n-9 (Palmitoleic) & $5.429 \pm 1.107$ & $3.837 \pm 0.333$ & $3.467 \pm 0.470$ & 0.2907 \\
\hline C18:1n-9 (Oleic) & $34.674 \pm 3.855$ & $34.279 \pm 1.763$ & $33.626 \pm 2.486$ & 0.9379 \\
\hline C20:1n-9 (Eicosenoic) & $1.646 \pm 1.075$ & $2.424 \pm 0.384$ & $1.829 \pm 0.541$ & 0.3757 \\
\hline MUFA & $39.224 \pm 4.899$ & $40.541 \pm 1.776$ & $38.924 \pm 2.505$ & 0.7707 \\
\hline C18:2n-6 (Linoleic) & $22.838 \pm 3.009$ & $22.644 \pm 1.508$ & $24.971 \pm 2.127$ & 0.3214 \\
\hline C18:3n-6 (Linolenic) & $0.158 \pm 0.138$ & $0.113 \pm 0.041$ & $0.68 \pm 0.058$ & 0.5761 \\
\hline C20:2n-6 (Eicosadienoic) & $1.267 \pm 0.804$ & $1.687 \pm 0.242$ & $1.513 \pm 0.341$ & 0.7911 \\
\hline C20:3n-6 (Homolinolenic) & $0.139 \pm 0.168$ & $0.179 \pm 0.050$ & $0.243 \pm 0.071$ & 0.4402 \\
\hline C20:4n-6 (Arachidonic) & $0.145 \pm 0.115^{\mathrm{a}}$ & $0.150 \pm 0.105^{a}$ & $0.453 \pm 0.149^{b}$ & 0.0282 \\
\hline PUFA & $27.864 \pm 3.033$ & $24.774 \pm 1.515$ & $27.350 \pm 2.137$ & 0.3266 \\
\hline$\omega 3 \mathrm{FA}$ & $1.395 \pm 0.842$ & $1.134 \pm 0.253$ & $1.291 \pm 0.357$ & 0.8691 \\
\hline$\omega 6 \mathrm{FA}$ & $25.380 \pm 3.185$ & $23.250 \pm 1.561$ & $25.644 \pm 2.201$ & 0.3371 \\
\hline$\omega 9 \mathrm{FA}$ & $39.077 \pm 4.933$ & $38.116 \pm 1.786$ & $37.094 \pm 2.519$ & 0.9032 \\
\hline
\end{tabular}

IMF, intramuscular fat content; SFA, saturated fatty acids (C14:0+C16:0+C18:0+C20:0); MUFA, monounsaturated fatty acids (C16:1n-9+C18:1n-9+C20:1n-9); PUFA, polyunsaturated fatty acids (C18:2n-6+C18:3n-6+C20:2n-6+C20:3n-6+C20:4n-6); $\omega 3$ fatty acids (C18:3n-3+C20:5n-3+C22:6n-3); $\omega 6$ fatty acids (C18:2n-6+C18:3n-6+C20:3n-6); $\omega 9$ fatty acids (C16:1n-9+C18:1n-9).

a,b Values in each row with different superscript letters are considered significantly different $(p<0.05)$.

was located at position $4.93 \mathrm{Mb}$ on porcine chromosome 7 close to the porcine ras responsive element binding protein 1 (RREB1, $4.59 \mathrm{Mb})$ gene. The RREB1 gene encodes a zinc finger transcription factor [14]. It is involved in regulating the renin-angiotensin system. The RREB1 variants showed an association with type 2 diabetes and end-stage kidney disease in humans [15]. It has been reported that the RREB1 was associated with fat distribution and fasting glucose displaying potential effects related to the observed type 2 diabetes association [14,15]. Moreover, the type 2 diabetes locus was identified in the RREB1 region [16].

The SSC8 g.47338181G>A marker derived from the primer combination E-AGC/T-CTG (AFLP10) was located at position $47.33 \mathrm{Mb}$ on porcine chromosome 8 close to the porcine guanylate cyclase 1 soluble beta 3 (GUCY1B3) $(46.71 \mathrm{Mb})$ gene. The GUCY1B3 gene is a beta subunit of the soluble guanylate cyclase and belongs to the nitric oxide system. It is involved in adipose tissue biology by influencing adipogenesis, insulinstimulated glucose uptake and lipolysis [17]. Several studies have reported on the importance of the presence of QTL for lipid accretion and IMF content on SSC8 $[7,8]$. Although the AFLP10 revealed significant differences in frequency between the two groups of high- and low-IMF contents, the SNP detected in this fragment had no effect on the IMF and FA composition traits. The results indicate a lack of linkage disequilibrium between this SNP marker and the causal mutations for the studied traits in these crossbred pigs.
The SSC9 g.5496647_5496662insdel marker secured from the primer combination E-ATC/T-CGT was located at position $5.49 \mathrm{Mb}$ on porcine chromosome 9 close to the porcine olfactory receptor family 51 , subfamily $\mathrm{V}$, member 1 (OR51V1, $5.46 \mathrm{Mb}$ ) gene. The olfactory receptor genes are a member of a large family of G-protein-coupled receptors and are encoded with single coding-exon genes. Olfactory receptors reveal a seven-transmembrane domain structure and are specifically responsible for the recognition and $\mathrm{G}$ protein-mediated transduction of odorant signals [18]. However, the molecular basis of the olfactory receptors for controlling fat deposition in animals is poorly understood. It has been indicated that the olfactory receptors may play a role in the sensing and regulation of dietary fat, and may be important with regard to the individual susceptibility of obesity in rats [19]. Moreover, the increasing expression levels of the olfactory receptor genes have been identified in adipose tissue during the development of obesity in mice [20]. In the present study, the SSC9 g.5496647_5496662insdel marker showed a significant association with IMF content and arachidonic levels. This result is consistent with those of previous studies which found that the QTLs for IMF content and fatty acid composition were located on the SSC9 at position 5.9 to $6.0 \mathrm{Mb}$ [21] and 11.1 to $17.8 \mathrm{Mb}$ [5], respectively.

The SSC10 g.71225134G >A marker derived from the primer combination E-ACG/T-CTG showed 99\% homology with porcine ANKRD16 gene and was located at position $71.2 \mathrm{Mb}$ of porcine chromosome 10. In this study, the SSC10 g.71225134G $>$ A 
Table 7. Association of the SSC10 g.71225134G>A marker with IMF content and fatty acid composition traits in longissimus dorsi muscwles in commercially crossbred pigs

\begin{tabular}{|c|c|c|c|}
\hline \multirow[t]{2}{*}{ Traits (\%) } & \multicolumn{2}{|c|}{$\begin{array}{c}\text { Genotypes } \\
\text { (Least squares mean } \pm \text { standard error) }\end{array}$} & \multirow[t]{2}{*}{$p$-value } \\
\hline & AA $(n=198)$ & $A G(n=57)$ & \\
\hline IMF & $2.287 \pm 0.121$ & $2.397 \pm 0.282$ & 0.7155 \\
\hline C14:0 (Myristic) & $1.085 \pm 0.050$ & $1.208 \pm 0.171$ & 0.2614 \\
\hline C16:0 (Palmitic) & $13.084 \pm 0.811$ & $11.539 \pm 2.333$ & 0.5121 \\
\hline C18:0 (Stearic) & $11.384 \pm 0.646$ & $13.692 \pm 1.858$ & 0.2224 \\
\hline C20:0 (Arachidic) & $0.263 \pm 0.048$ & $0.323 \pm 0.140$ & 0.6680 \\
\hline SFA & $25.819 \pm 1.127$ & $26.834 \pm 3.302$ & 0.7210 \\
\hline C16:1n-9 (Palmitoleic) & $3.860 \pm 0.243^{\mathrm{a}}$ & $5.323 \pm 0.699^{b}$ & 0.0440 \\
\hline C18:1n-9 (Oleic) & $34.576 \pm 0.919$ & $36.785 \pm 2.366$ & 0.3480 \\
\hline C20:1n-9 (Eicosenoic) & $2.010 \pm 0.225$ & $1.581 \pm 0.648$ & 0.5126 \\
\hline MUFA & $40.160 \pm 1.045$ & $44.119 \pm 2.692$ & 0.1436 \\
\hline C18:2n-6 (Linoleic) & $25.510 \pm 1.213$ & $22.110 \pm 3.491$ & 0.3364 \\
\hline C18:3n-6 (Linolenic) & $0.135 \pm 0.031$ & $0.134 \pm 0.092$ & 0.9963 \\
\hline C20:2n-6 (Eicosadienoic) & $1.689 \pm 0.180$ & $1.163 \pm 0.517$ & 0.3170 \\
\hline C20:3n-6 (Homolinolenic) & $0.181 \pm 0.038$ & $0.089 \pm 0.110$ & 0.4101 \\
\hline C20:4n-6 (Arachidonic) & $0.115 \pm 0.089$ & $0.034 \pm 0.257$ & 0.7549 \\
\hline PUFA & $27.632 \pm 1.227$ & $23.532 \pm 3.529$ & 0.2531 \\
\hline$\omega 3 \mathrm{FA}$ & $1.294 \pm 0.177$ & $0.907 \pm 0.603$ & 0.5257 \\
\hline$\omega 6 \mathrm{FA}$ & $26.155 \pm 1.257$ & $23.634 \pm 3.617$ & 0.3368 \\
\hline$\omega 9 \mathrm{FA}$ & $35.992 \pm 1.291^{\mathrm{a}}$ & $44.322 \pm 3.655^{b}$ & 0.0284 \\
\hline
\end{tabular}

IMF, intramuscular fat content; SFA, saturated fatty acids (C14:0+C16:0+C18:0+C20:0); MUFA, monounsaturated fatty acids (C16:1n-9+C18:1n-9+C20:1n-9); PUFA, polyunsaturated fatty acids (C18:2n-6+C18:3n-6+C20:2n-6+C20:3n-6+C20:4n-6); $\omega 3$ fatty acids (C18:3n-3+C20:5n-3+C22:6n-3); $\omega 6$ fatty acids (C18:2n-6+C18:3n$6+(20: 3 n-6) ; \omega 9$ fatty acids $(C 16: 1 n-9+C 18: 1 n-9)$.

$a, b$ Values in each row with different superscript letters are considered significantly different $(p<0.05)$. marker revealed a significant association with palmitoleic and $\omega 9$ FA levels. However, this SNP was identified in the non-coding regions of the porcine $A N K R D 16$ gene. It has been hypothesized that the SSC10 g.71225134G $>$ A might be in linkage disequilibrium with other causal polymorphisms, which may be located in another region of the ANKRD16 gene. There is a limited amount of information regarding the ANKRD16 gene and its potential functions relating to fat deposition in pigs. However, a previous study pointed to multiple QTLs in the location of 68.0 to $76.9 \mathrm{Mb}$ on SSC10, and was associated with serum lipid traits in pigs [22].

In this study, the SSC17 g.61976696G>T marker showed a significant association with IMF content and FA composition of palmitoleic, eicosenoic, arachidonic, MUFA, and $\omega 9$ FA levels. This marker derived from the primer combination E-ACC/TCTA was located at $61.9 \mathrm{Mb}$ of porcine chromosome 17 close to the porcine cytochrome P450 family 24 subfamily A member 1 (CYP24A1, 61.89 Mb) and docking protein 5 (DOK5, 62.40 $\mathrm{Mb})$ genes. The CYP24A1 is a catabolic vitamin-D-24-hydroxylase enzyme [23] and belongs to a member of the oxygenase cytochrome P450 genes [20]. It is expressed in adipose tissue and showed a relationship with obesity in humans [24]. The trans-regulated CYP24A1 gene revealed an association with palmitic and saturated FA contents in the muscle tissue of pigs [25]. The DOK5 gene belongs to the downstream of the kinase family [26]. It is a substrate in the insulin signaling and is highly expressed in skeletal muscles [27]. The DOK5 exhibited

Table 8. Association of the SSC17g.61976696G>T marker with IMF content and fatty acid composition traits in longissimus dorsi muscles in commercially crossbred pigs

\begin{tabular}{|c|c|c|c|c|}
\hline \multirow{2}{*}{ Traits (\%) } & \multicolumn{3}{|c|}{ Genotypes (Least squares mean \pm standard error) } & \multirow{2}{*}{$\mathrm{p}$-value } \\
\hline & GG $(n=175)$ & GT $(n=127)$ & $T T(n=52)$ & \\
\hline IMF & $2.104 \pm 0.128^{\mathrm{a}}$ & $2.594 \pm 0.195^{b}$ & $2.172 \pm 0.335^{\mathrm{ab}}$ & 0.0451 \\
\hline C14:0 (Myristic) & $1.123 \pm 0.068$ & $1.020 \pm 0.086$ & $1.035 \pm 0.127$ & 0.5482 \\
\hline C16:0 (Palmitic) & $13.107 \pm 1.013$ & $12.797 \pm 1.270$ & $11.354 \pm 1.875$ & 0.6481 \\
\hline C18:0 (Stearic) & $11.768 \pm 0.812$ & $12.327 \pm 1.019$ & $10.808 \pm 1.054$ & 0.6829 \\
\hline C20:0 (Arachidic) & $0.301 \pm 0.062$ & $0.291 \pm 0.078$ & $0.321 \pm 0.115$ & 0.9702 \\
\hline SFA & $26.301 \pm 1.373$ & $26.437 \pm 1.722$ & $23.519 \pm 2.542$ & 0.2927 \\
\hline C16:1n-9 (Palmitoleic) & $4.250 \pm 0.246^{b}$ & $3.008 \pm 0.309^{\mathrm{a}}$ & $3.175 \pm 0.356^{\mathrm{a}}$ & 0.0153 \\
\hline C18:1n-9 (Oleic) & $37.334 \pm 1.145$ & $34.459 \pm 1.436$ & $38.881 \pm 2.120$ & 0.0967 \\
\hline C20:1n-9 (Eicosenoic) & $2.322 \pm 0.372^{b}$ & $1.726 \pm 0.467^{\mathrm{a}}$ & $1.846 \pm 0.489^{a}$ & 0.0491 \\
\hline MUFA & $43.906 \pm 1.278^{b}$ & $39.194 \pm 1.603^{\mathrm{a}}$ & $38.904 \pm 1.565^{\mathrm{a}}$ & 0.0255 \\
\hline C18:2n-6 (Linoleic) & $22.760 \pm 1.523$ & $22.848 \pm 1.910$ & $23.422 \pm 2.819$ & 0.9722 \\
\hline C18:3n-6 (Linolenic) & $0.145 \pm 0.039$ & $0.107 \pm 0.049$ & $0.210 \pm 0.073$ & 0.4165 \\
\hline C20:2n-6 (Eicosadienoic) & $1.596 \pm 0.224$ & $1.403 \pm 0.281$ & $1.242 \pm 0.415$ & 0.6608 \\
\hline C20:3n-6 (Homolinolenic) & $0.127 \pm 0.047$ & $0.210 \pm 0.059$ & $0.288 \pm 0.088$ & 0.1730 \\
\hline C20:4n-6 (Arachidonic) & $0.125 \pm 0.014^{a}$ & $0.285 \pm 0.011^{b}$ & $0.120 \pm 0.021^{\mathrm{a}}$ & 0.0432 \\
\hline PUFA & $24.655 \pm 1.538$ & $24.756 \pm 1.929$ & $25.370 \pm 2.847$ & 0.9684 \\
\hline$\omega 3 \mathrm{FA}$ & $1.164 \pm 0.254$ & $1.100 \pm 0.319$ & $1.201 \pm 0.234$ & 0.7431 \\
\hline$\omega 6 \mathrm{FA}$ & $23.297 \pm 1.575$ & $23.377 \pm 1.975$ & $24.200 \pm 2.915$ & 0.9510 \\
\hline$\omega 9 \mathrm{FA}$ & $41.584 \pm 1.274^{b}$ & $37.468 \pm 1.598^{\mathrm{a}}$ & $37.638 \pm 1.859^{\mathrm{a}}$ & 0.0472 \\
\hline
\end{tabular}

IMF, intramuscular fat content; SFA, saturated fatty acids (C14:0+C16:0+C18:0+C20:0); MUFA, monounsaturated fatty acids (C16:1n-9+C18:1n-9+C20:1n-9); PUFA, polyunsaturated fatty acids (C18:2n-6+C18:3n-6+C20:2n-6+C20:3n-6+C20:4n-6); $\omega 3$ fatty acids (C18:3n-3+C20:5n-3+C22:6n-3); $\omega 6$ fatty acids (C18:2n-6+C18:3n-6+C20:3n-6); $\omega 9$ fatty acids (C16:1n-9+C18:1n-9).

$a, b$ Values in each row with different superscript letters are considered significantly different $(p<0.05)$. 
a strong association with obesity and type 2 diabetes in humans [26]. Additionally, several QTLs for IMF content and fatty acid composition traits have been identified and located within the regions at position 57.6 to $67.9 \mathrm{Mb}$ on SSC17 [28,29]. These results suggest that the SSC17 g.61976696G $>$ T might be in linkage disequilibrium with CYP24A1 and DOK5 genes.

These results highlight the importance of the selected AFLP markers. They can be used to identify the effective SNP markers for IMF content and FA composition in the muscle tissue of pigs. Additionally, the in silico mapping showed that the AFLP markers were located on SSC7, SSC8, SSC9, SSC10, and SSC17 and were mapped close to the strong functional candidate genes for fatness traits including, RREB1, GUCY1B3, OR51V1, $A N K R D 16, C Y P 24 A 1$, and DOK5, respectively. These findings promote the importance of all genes as the positional candidate genes for fat deposition in the muscles of pigs. Further studies on the single nucleotide polymorphisms of these genes are required in order to identify their association with fat deposition in muscles.

In the current study, we have identified the AFLP markers for IMF content and FA composition. Four novel SNP markers (SSC7 g.4937240C>G, SSC9 g.5496647_5496662insdel, SSC10 g.71225134G >A, and SSC17 g.61976696G >T) were found to be associated with IMF and/or FA content traits in commercially crossbred pigs. We demonstrated the possibility of taking advantage of the AFLP approach with regards to identification of the positional candidate genes for fat deposition in the muscle tissue of pigs.

\section{CONFLICT OF INTEREST}

We certify that there is no conflict of interest with any financial organization regarding the material discussed in the manuscript.

\section{ACKNOWLEDGMENTS}

This research was partially supported by the Center of Excellence on Agricultural Biotechnology, Science and Technology Postgraduate Education and Research Development Office, Office of Higher Education Commission, Ministry of Education, Thailand (AG-BIO/PERDO-CHE) and the Joint Venture Project of Research and Development of Government-Private Sectors in Commercialization, Bureau of Cooperation and Promotion, Office of Higher Education Commission, Ministry of Education, Thailand. We would like to acknowledge Chiang Mai University for extending the support of a Postdoctoral Fellowship to T. Kumchoo. We would like to thank the Betagro Hybrid International Company, Thailand for providing us with the pork samples used in this study. Determination of intramuscular fat content and fatty acid composition was completed with the great help from N. Pothakam.

\section{REFERENCES}

1.Faucitano L, Rivest J, Daigle JP, Lévesque J, Gariepy C. Distribution of intramuscular fat content and marbling within the longissimus muscle of pigs. Can J Anim Sci 2004;84:57-61.

2.Sanchez MP, Iannuccelli N, Basso B, et al. Identification of QTL with effects on intramuscular fat content and fatty acid composition in a Duroc×Large White cross. BMC Genet 2007;8:55.

3.Ruść A, Sieczkowska H, Krzęcio E, et al. The association between acyl-CoA synthetase (ACSL4) polymorphism and intramuscular fat content in (Landrace $\times$ Yorkshire) $\times$ Duroc pigs. Meat Sci 2011; 89: 440-3.

4.Quintanilla R, Pena RN, Gallardo D, et al. Porcine intramuscular fat content and composition are regulated by quantitative trait loci with muscle-specific effects. J Anim Sci 2011;89:2963-71.

5.Uemoto Y, Soma Y, Sato S, et al. Genome-wide mapping for fatty acid composition and melting point of fat in a purebred Duroc pig population. Anim Genet 2012;43:27-34.

6.Ramayo-Caldas Y, Mercadé A, Castelló A, et al. Genome-wide association study for intramuscular fatty acid composition in an Iberian×Landrace cross. J Anim Sci 2012;90:2883-93.

7.Muñoz M, Rodríguez MC, Alves E, et al. Genome-wide analysis of porcine backfat and intramuscular fat fatty acid composition using high-density genotyping and expression data. BMC Genomics 2013;14:845.

8.Nonneman DJ, Shackelford SD, King DA, et al. Genome-wide association of meat quality traits and tenderness in swine. J Anim Sci 2013;91:4043-50.

9. Yang B, Zhang W, Zhang Z, et al. Genome-wide association analyses for fatty acid composition in porcine muscle and abdominal fat tissues. PLoS One 2013;8:65554.

10. Kim SW, Li XP, Lee YM, et al. QTL scan for meat quality traits using high-density SNP chip analysis in cross between Korean native pig and Yorkshire. Asian-Australas J Anim Sci 2011;24:1184-91.

11. Wimmers K, Murani E, Ponsuksili S, Yerle M, Schellander K. Detection of quantitative trait loci for carcass traits in the pig by using AFLP. Mamm Genome 2002;13:206-10.

12. Xiao Q, Wibowo TA, Wu XL, et al. A simplified QTL mapping approach for screening and mapping of novel AFLP markers associated with beef marbling. J Biotechnol 2007;127:177-87.

13. Jiao S, Maltecca C, Gray KA, Cassady JP. Feed intake, average daily gain, feed efficiency, and real-time ultrasound traits in Duroc pigs: II. Genomewide association. J Anim Sci 2014;92:2846-60.

14. Scott RA, Lagou V, Welch RP, et al. Large-scale association analyses identify new loci influencing glycemic traits and provide insight into the underlying biological pathways. Nat Genet 2012; 44:991-1005.

15. Bonomo JA, Guan M, Ng MC, et al. The ras responsive transcription factor RREB1 is a novel candidate gene for type 2 diabetes associated end-stage kidney disease. Hum Mol Genet 2014;23:6441-7.

16. DIAbetes Genetics Replication And Meta-analysis (DIAGRAM) Consortium, Asian Genetic Epidemiology Network Type 2 Diabetes 
(AGEN-T2D) Consortium, South Asian Type 2 Diabetes (SAT2D) Consortium, et al. Genome-wide trans-ancestry meta-analysis provides insight into the genetic architecture of type 2 diabetes susceptibility. Nat Genet 2014;46:234-44.

17. Engeli S, Janke J, Gorzelniak K, et al. Regulation of the nitric oxide system in human adipose tissue. J Lipid Res 2004;45:1640-8.

18. Giandomenico V, Cui T, Grimelius L, Öberg K, Pelosi G, Tsolakis $\mathrm{AV}$. Olfactory receptor 51E1 as a novel target for diagnosis in somatostatin receptor-negative lung carcinoids. J Mol Endocrinol 2013; 51:277-86.

19. Primeaux SD, Braymer HD, Bray GA. High fat diet differentially regulates the expression of olfactory receptors in the duodenum of obesity-prone and obesity-resistant rats. Dig Dis Sci 2013;58: 72-6.

20. Choi Y, Hur CG, Park T. Induction of olfaction and cancer-related genes in mice fed a high-fat diet as assessed through the mode-ofaction by network identification analysis. PLoS One 2013;8:56610.

21. Sato S, Oyamada Y, Atsuji K, et al. Quantitative trait loci analysis for growth and carcass traits in a Meishan $\times$ Duroc F2 resource population. J Anim Sci 2003;81:2938-49.

22. Manunza A, Casellas J, Quintanilla R, et al. A genome-wide association analysis for porcine serum lipid traits reveals the existence of age-specific genetic determinants. BMC Genomics 2014;15: 758.
23. Shen H, Bielak LF, Ferguson JF, et al. Association of the vitamin D metabolism gene CYP24A1 with coronary artery calcification. Arterioscler Thromb Vasc Biol 2010;30:2648-54.

24. Gularte-Mérida R, Farber CR, Verdugo RA, et al. Overlapping mouse subcongenic strains successfully separate two linked body fat QTL on distal MMU 2. BMC Genomics 2015;16:16.

25. Cánovas A, Pena RN, Gallardo D, Ramírez O, Amills M, Quintanilla R. Segregation of regulatory polymorphisms with effects on the gluteus medius transcriptome in a purebred pig population. PLoS One 2012;7:35583.

26. Tabassum R, Mahajan A, Chauhan G, et al. Evaluation of DOK5 as a susceptibility gene for type 2 diabetes and obesity in North Indian population. BMC Med Genet 2010;11:35.

27. Cai D, Dhe-Paganon S, Melendez PA, Lee J, Shoelson SE. Two new substrates in insulin signaling, IRS5/DOK4 and IRS6/DOK5. J Biol Chem 2003;278:25323-30.

28. Ma J, Ren J, Guo Y, et al. Genome-wide identification of quantitative trait loci for carcass composition and meat quality in a large-scale White Duroc $\times$ Chinese Erhualian resource population. Anim Genet 2009;40: 637-47.

29. Rückert C, Stratz P, Preuss S, Bennewitz J. Mapping quantitative trait loci for metabolic and cytological fatness traits of connected F2 crosses in pigs. J Anim Sci 2012;90:399-409. 